\title{
Leaders
}

\section{Leptin: of mice and men?}

\author{
L Bowles, P Kopelman
}

\begin{abstract}
A major advance in the understanding of the control of appetite, food intake, and energy expenditure came with the discovery of leptin. Leptin concentrations correlate with adipose tissue mass, and leptin acts via the central nervous system (CNS) to reduce food intake and increase energy expenditure. A variety of different neurotransmitters have been implicated in mediating the CNS effects of leptin. In humans, leptin deficiency is unlikely to be a major cause of obesity. Most humans are not leptin deficient, but have a leptin concentration raised in proportion to their fat mass. A recent clinical trial looking at the use of recombinant leptin in treating human obesity has resulted in only variable amounts of weight loss. The role of leptin extends beyond the control of food intake and energy expenditure. Leptin reverses many of the physiological responses to starvation. It is suggested that the main role of leptin might be in response to food deprivation and not in obesity.

(F Clin Pathol 2001;54:1-3)
\end{abstract}

Keywords: leptin; leptin receptor; obesity; insulin resistance

The prevalence of obesity is growing at a worrying rate throughout the world. In England and Wales, the latest prevalence figures indicate that the rate has more than doubled since 1980. This explosion in the frequency of obesity has occurred in the face of an increasing understanding of the pathophysiological consequences and associated health hazards. The major determinant of this increase in such a short space of time is the sedentary nature of modern life that has not been parallelled by an appropriate reduction in energy intake. Irrespective of these factors, it is acknowledged that underlying genetic and molecular mechanisms are important and, as a consequence, the drive to identify these has become even more intense.

A major breakthrough came with the discovery of leptin by Zhang et al. ${ }^{1}$ When the ob gene was cloned, it was found to encode a $16 \mathrm{kDa}$ protein, which has been called leptin. Recessive mutations in the ob gene lead to defective production of leptin, with the ob/ob mouse becoming obese, insulin resistant, and infertile from early life. Intraperitoneal injections of leptin into ob/ob mice result in a fall in body weight within days and by 33 days $40 \%$ of the original weight is lost. Leptin effects this weight loss in the ob/ob mouse by both a profound reduction in food intake and an increase in energy expenditure. ${ }^{2}$ Leptin mRNA is mostly expressed in white adipose tissue and leptin induced weight loss is restricted to these areas. In contrast, diet induced weight loss leads to loss of both lean and adipose tissue. Leptin can be found circulating in both free and bound forms. Leptin appears to be an afferent signal that indicates the size of fat stores, and plasma leptin concentrations correlate closely with adipose tissue mass in human and animal models. $^{3}$

Several different forms of specific Ob-R receptors for leptin have been identified in the central nervous system (CNS) as well as peripheral structures such as lung, kidney, and liver. ${ }^{4}$ Mutations of the Ob-R receptor are associated with rodent obesity. The $\mathrm{db} / \mathrm{db}$ mouse, which is phenotypically identical to the ob/ob mouse, has, by contrast, high circulating concentrations of leptin. The $\mathrm{db}$ mutation encodes the cytoplasmic domain of the leptin receptor and therefore leads to a state of leptin resistance through the production of a faulty receptor. $^{5}$

The main site of action for leptin is the CNS, which it enters via a saturable transport system. ${ }^{6}$ Leptin receptors are expressed in a variety of different areas of the brain, including the hypothalamus. When leptin is administered into the lateral ventricles of ob/ob mice they show a reduced food intake within 30 minutes. $^{7}$ The CNS effects of leptin are mediated through several different neurotransmitters. Neuropeptide $\mathrm{Y}$ is a potent stimulator of food intake and its production is inhibited by leptin. Leptin reduces the amount of pre-proneuropeptide mRNA in cells from the hypothalamus in the ob/ob mouse. ${ }^{8}$ Nevertheless, other pathways are also important because neuropeptide $\mathrm{Y}$ deficient mice have normal body weights and food intake. ${ }^{9}$ Proopiomelanocortin (POMC) appears to be an important second messenger in the leptin pathway. POMC neurones express mRNA for the long form of the leptin receptor in the arcuate nucleus and leptin modulates POMC gene expression. ${ }^{10}$ In addition, linkage between leptin and a region of chromosome 2, containing the POMC locus, 
has been described. ${ }^{11}$ POMC is cleaved to form $\alpha$-melanocyte stimulating hormone (MSH) and adrenocorticotrophic hormone (ACTH). ${ }^{12}$ $\alpha-\mathrm{MSH}$ acts via the melanocortin 4 receptor (MC4-R) in the hypothalamus to reduce food intake and increase energy expenditure. ${ }^{13}$ In the yellow mouse model there is increased production of agouti, a protein that is normally synthesised in hair follicles and antagonises the effects of MSH via blockage of the MC4-R. Agouti was found to antagonise the MC4-R in the hypothalamus and it is postulated that this receptor blockade leads to obesity. ${ }^{14}$ MC4-R knockout mice are obese. ${ }^{15}$ Furthermore, agouti related transcript (ART) is an endogenous antagonist of melanocortin signalling and overexpression results in obesity. ${ }^{16}$

In rodent models, leptin appears to have other important effects, which extend beyond those controlling food intake and energy expenditure. The treatment of infertile female $\mathrm{ob} / \mathrm{ob}$ mice with leptin restores fertility. ${ }^{17}$ Interestingly, fertility is also restored when pituitary/ hypothalamic extracts from normal mice are placed into ob/ob mice. Similarly, ovulation occurs if the non-functioning ovaries of ob/ob mice are transplanted into a normal mouse. ${ }^{18}$ These findings suggest a defect in the hypothalamic-pituitary system. Moreover, leptin is important for the onset of sexual maturity and puberty by acting as a signal to the reproductive system when adequate fat stores are available to meet the demands of reproduction. ${ }^{19}$

Reductions in leptin concentrations might be important in the physiological response to starvation. During starvation, the thyroid and growth hormone axes are suppressed to help conserve energy. In addition, fertility is reduced so that reproduction only takes place during times of plenty when the energy demands of pregnancy and lactation can be met. There is also an increase in glucocorticoid hormone release. Leptin administration in mice reverses the starvation induced suppression of the thyroid axis and inhibits the release of glucocorticoid; on this basis, it is has been proposed that leptin might play a major physiological role in the control of the neuroendocrine responses to fasting. ${ }^{2021}$ Leptin receptors are expressed in a wide range of peripheral tissues and further research is needed to define all of the physiological actions of this molecule.

The initial hypothesis that obesity in humans results from a relative or absolute deficiency of leptin has not been borne out. Paradoxically, most obese humans have high circulating concentrations of leptin that are raised in proportion to fat mass, ${ }^{3}$ whereas only a handful of individuals with severe obesity have been identified with congenital deficiency ${ }^{22}$ or a mutation in the leptin receptor gene. ${ }^{23}$ Human obesity could represent a state of leptin resistance because the high concentrations of leptin do not induce an appropriate reduction in food intake. Theoretically, leptin resistance could result from mutations of the leptin receptor or one or more of the genes "downstream" of the leptin receptor-for example, POMC or MC4-R. Accordingly, congenital mutations in the leptin receptor associated with obesity have been described ${ }^{23}$; mutations in the POMC gene result in humans with obesity, red hair, and adrenal insufficiency ${ }^{24}$; and frameshift mutations in MC4-R have been demonstrated in a cohort of severely obese children. ${ }^{25}$ Another potential source for leptin resistance is the "suppressor of cytokine signalling 3" (SOCS3). In cell lines, SOCS-3 blocks leptin induced signal transduction. ${ }^{26}$ However, it should be recognised that these mutations probably only account for a minority of cases of obesity in the general population.

Detailed observations of a child with severe, early onset obesity treated with subcutaneous injections of leptin has demonstrated significant and impressive weight loss without any alteration in 24 hour energy expenditure-a reduction in basal metabolic rate was counterbalanced by an increase in physical activity. ${ }^{27}$ The chief effect of leptin in inducing weight loss was mediated by its suppressive effect on food intake. However, an initial improvement in gonadotrophin responsiveness to stimulation by gonadotrophin releasing hormone, and the establishment of gonadotrophin pulsatility at 12 months of treatment, does not appear to have been maintained after 18 months, suggesting that the child may be regressing to the previous hypogonadotrophic state. Furthermore, the anticipated fall in circulating plasma insulin concentrations has not been seen, which is in contrast to the ob/ob mouse, where a dramatic reduction in insulin is seen with leptin administration. Antibodies to the administered leptin were detected after two months of treatment and required an increase in the leptin dose. The findings in this child raise important questions about the primary role of leptin and demonstrate the complexity of hypothalamic function in humans compared with rodents. In a recent randomised, double blind, placebo controlled trial, 73 obese individuals, with plasma leptin values raised appropriate to their weight, received subcutaneous recombinant methionyl human leptin (r-leptin) over a 24 week period. Subjects were randomised to receive one of four increasing doses of r-leptin. They were also prescribed an energy restricted diet and exercise programme. Most, but not all, of the subjects receiving r-leptin lost a modest amount of weight. This weight loss was irrespective of their endogenous leptin concentration. However, there was considerable variability in the amount of weight lost, with those on the highest dose of r-leptin losing the most weight. ${ }^{28}$

These preliminary results underline the need for caution when extrapolating from mice to humans. Indeed, they support speculation that leptin's main role in human physiology is to defend or protect body fat stores rather than regulate their appreciation. From a teleological viewpoint, it is likely that leptin's major functions evolved from a situation of human famine and scarcity of food rather than excess. A decrease in leptin would therefore be accompanied by a preservation of energy stores accompanied by an inhibition in reproductive ability and a reduction in anabolic hormones 
such as insulin, growth hormone, and thyroid hormone.

Clearly then, leptin's role in human physiology is not limited to defending body fat stores. Given that the ob gene shows homology across a variety of different species, it would be unusual for it to have been selected through evolution for primarily an antiobesity function, particularly when human survival was formerly dependent on the maintenance of body fat stores. Thus, it is possible that the most important actions of leptin result from a fall in its plasma values with a major role to improve survival when food is scarce. ${ }^{29} \mathrm{~A}$ fall in leptin concentrations elicits several advantageous neuroendocrine adaptations, which include the suppression of the thyroid, growth hormone, and gonadal axes. Thus, it is arguable that interest in leptin should be focused more on studying leptin concentrations in situations of under nutrition and during periods of weight gain associated with pubertal development rather than obesity, particularly when a higher transport of leptin across the blood-brain barrier is seen at lower leptin concentrations. ${ }^{30}$ In anorexia nervosa, leptin concentrations are in proportion to the subjects body mass index, ${ }^{31}$ and these low leptin values are closely associated with the neuroendocrine responses that develop in response to fasting.

The spiralling prevalence of obesity across the world is having a great impact on health. The discovery of leptin is an important landmark in obesity research that has resulted in major advances in our knowledge about the pathogenesis of weight gain in animal models. The exact role that leptin plays in humans remains uncertain. Evidence to date suggests that alteration in leptin is not a causative factor in the development of most instances of human obesity, but merely a marker of fat stores. Nevertheless, the evidence from animal models, and circumstantial findings from humans, confirms that leptin has important roles in both the protection of depleted fat stores and as a trigger for reproductive ability. We suggest that leptin research needs to define these functions for the future.

1 Zhang Y, Proenca R, Maffei M, et al. Positional cloning of the mouse obese gene and its human homologue. Nature 1994;372:425-32.

2 Halaas J, Gajiwala K, Maffei M, et al. Weight reducing effects of the plasma protein encoded by the ob gene. Science 1995;269:543-6.

3 Maffei M, Halaas J, Ravussin E, et al. Leptin levels in human and rodent: measurement of plasma leptin and ob RNA in abese and weight reduced subjects. Nat Med 1995;11: obese and

4 Tartaglia L, Demski M, Weng X, et al. Identification and expression cloning of a leptin receptor, OB-R. Cell 1995;83:1263-71.
5 Lee GH, Procenca R, Montez JM, et al. Abnormal splicing of the leptin receptor in diabetic mice. Nature 1996;379: 632-5.

6 Banks WA, Kastin AJ, Huang W, et al. Leptin enters the brain via a saturable system independent of insulin. Peptides 1996;17:305-11.

7 Campfield LA, Smith FJ, Guisez Y, et al. Recombinant mouse ob protein: evidence for a peripheral signal linking adiposity and central neural networks. Science 1995;280: 546-9.

8 Stephens TW, Basinski TW, Bristow PK, et al. The role of neuropeptide $\mathrm{Y}$ in the anti-obesity action of the obese gene product. Nature 1995;377:530-2.

9 Erickson JC, Clegg KE, Palmiter RD. Sensitivity to leptin and susceptibility to seizures in mice lacking neuropeptide Y. Nature 1996;381:415-21.

10 Thornton J, Cheung C, Clifton D, et al. Regulation of hypothalamic proopiomelanocortin mRNA by leptin in ob/ob mice. Endocrinology 1997;138:5063-6.

11 Comuzzie A, Hixson J, Almasy L, et al. A major quantative trait locus determining serum leptin and fat mass is located on human chromosome 2. Nat Genet 1997;15:273-5.

12 Mountjoy K, Wong. Obesity, diabetes and functions for proopiomelanocortin-derived peptides. Mol Cell Endocrinol 1997;128:171-7.

13 Fan W, Boston B, Keterson R, et al. Role of melanocortinergic neurones in feeding and the agouti obesity syndrome. Nature 1997;385:165-8.

$14 \mathrm{Lu}$ D, Willard D, Patel IR, et al. Agouti protein is an antagonist of the melanocyte-stimulating-hormone receptor. Nature 1994;371:799-802.

15 Huzuar D, Lynch C, Fairchild-Huntress V, et al. Targeted disruption of the melanocortin-4 receptor results in obesity in mice. Cell 1997;88:131-41.

16 Ollmann M, Wilson B, Yang Y, et al. Antagonism of central melanocortin receptors in vitro and in vivo by agoutirelated protein. Science 1997;278:135-8.

17 Chehab, FF, Lim ME, Lu R. Correction of sterility defect in homozygous obese female mice by treatment with recombinant leptin. Nat Genet 1996;12:318-20.

18 Spicer L, Francisco C. The adipose obese gene product, leptin: evidence of a direct inhibitory role in ovarian function. Endocrinology 1997;138:3374-9.

19 Barash IA, Cheung CC, Weigle DS, et al. Leptin is a signal to the reproductive system. Endocrinology 1996;137:3144-

20 Ahima R, Prabakaran D, Mantzorors CS, et al. Role of leptin in the neuroendocrine response to fasting. Nature 1996; 382:250-2.

21 Caro E, Senaris R, Considine RV, et al. Regulation of in vivo growth hormone secretion by leptin. Endocrinology 1997; 138:2203-6.

22 Montague CT, Farooqi S, Whitehead JP, et al. Congenital leptin deficiency is associated with severe early onset obesity. Nature 1997;387:903-8.

23 Clement KC, Vaisse C, Lahlou N, et al. A mutation in the human leptin receptor gene causes obesity and pituitary dysfunction. Nature 1998;392:398-401.

24 Krude H, Biebermann H, Luck W, et al. Severe early onset obesity, adrenal insufficiency and red hair pigmentation caused by POMC mutations in humans. Nat Genet 1998;19:155-7.

25 Yeo G, Farooqi S, Aminan S, et al. A frameshift mutation in MC4-R associated with dominantly inherited obesity. Nat Genet 1998;20:111-12.

26 Bjorbaek C, Elmquist J, Frantz J, et al. Identification of SOCS-3 as a potential mediator of central leptin resistance. Molecular Cell 1998;1;619-25.

27 Farooqi IS, Jebb SA, Langmack G, et al. Effects of recombinant leptin therapy in a child with congenital leptin deficiency. N Engl f Med 1999;341:879-84.

28 Hemysfield SB, Greenberg AS, Fujioka K, et al. Recombinant leptin for weight loss in obese and lean adults. fAMA 1999;282:1568-75.

29 Flier JS. What's in a name? In search of leptin's physiologic role. F Clin Endocrinol Metab 1998;83:1407-13.

30 Mantzoros CS, Flier JS, Lesem MD, et al. Cerebrospinal fluid leptin in anorexia nervosa: correlation with nutritional status and potential role in resistance to weight gain. $\mathcal{F}$ Clin Endocrinol Metab 1997;82:1845-51.

31 Grinspoon S, Gulick T, Askari H, et al. Serum leptin levels in women with anorexia nervosa. F Clin Endocrinol Metab 1996;81:3861-3. 